\title{
FRACTIONS OF HIPPOPHAE RHAMNOIDES TURKESTANICA EXTRACT AND THEIR ADAPTOGENIC AND IMMUNOMODULATORY POTENTIALS
}

\author{
*Priyanka Sharma ${ }^{\mathrm{a}}$, Geetha Suryakumar ${ }^{\mathrm{a}}$, Himanshi Tanwar ${ }^{\mathrm{b}}$, Kshipra Misrac ${ }^{\mathrm{c}}$ Lilly Ganju ${ }^{\mathrm{a}}$ \\ a Defence Institute of Physiology and Allied Sciences, Lucknow Road, Timarpur, Delhi-110054, India \\ ${ }^{\mathrm{b}}$ National Institute of Immunology, Aruna Asaf Ali Marg, Delhi-110067, India \\ 'Save the Environment, Heritage City, Gurugram, Haryana-122008, India
}

\begin{abstract}
Hippophae rhamnoides turkestanica (HRT)is capable of withstanding harsh climatic conditions prevalent at high altitude. Various medicinal and nutritional properties of the leaf-extract of this plant have already been established. In vitro studies of the extract ascertained the presence of various phyto constituents. In the present study adaptogenic and immunomodulatory potentials of different fractions of the whole leaf aqueous extract of HRT (SBT-5) are compared. This study was carried out on five fractions of SBT-5. Out of thefive fractions, polyphenolic rich fraction (PRF) showed $66.67 \%$ resistance against Cold-Hypoxia-Restraint(CHR) induced multiple stress at a four times lower dose compared to SBT-5. Supplementation of PRF significantly reduced the oxidative stress at tissues levels also. Successive Methanolic fraction amplified the immune response with Ovalbumin and Tetanus Toxoid antigens. As compared to SBT-5, PRF showed better antioxidant and adaptogenic potentials at four-time lower dose. This concludes that HRT fractions show improved performance under multiple stressful conditions as compared to the whole extract.
\end{abstract}

\section{Keywords}

Adaptogen, CHR,

Phytoconstituents, Polyphenols, Stress.

\section{Introduction}

Globally known plant that is capable to with stand harsh environment prevalent at high altitude is seabuckthorn (genus Hippophae). Hippophae rhamnoides turkestanica (HRT) is an Indian seabuckthorn species growing wildly in North-West Himalayas (7000-15000 ft.). It is a dwarf to tall (3-15 feet), branched, and thorny nitrogen fixing deciduous shrub, native to Europe and Asia (Singh et al. 2013). Our laboratory has done extensive research on this plant and established the anti-oxidative, anti-stress, adaptogen (Geetha et al. 2003; Saggu et al. 2006; Sharma et al. 2015) and wound healing (Gupta et al. 2005) properties in whole leaves' extract of HRT. Although the whole extract worked in ameliorating the high altitude induced stress, its active principles/ compounds were yet to be identified. Broadly these compounds can be categorized into various groups, i.e., polyphenols, organosulphurs, carotenoids, alkaloids, and nitrogen-containing compounds (Roy M and Datta A 2019). Both in vitro and in vivo studies on this plant have proved its bio efficacy (Olas B et al. 2018).

In this study the extract is further fractionated to identify the potent fraction that works under the target conditions. Very little information is available on the relationship between active components in the leaves of seabuckthorn to those of their antioxidant and immunomodulatory roles. This article demonstrates the adaptogenic, immune activating and antioxidant potentials of different fractions of HRT obtained using various solvents with increasing polarity. To the best of our knowledge HRT fractions are studied for the first time for their multiple anti-stress activities.

\section{Materials and Methods}

\section{Apparatus}

High Performance Thin Layer Chromatography (HPTLC), CAMAG, Switzerland; Cold-Hypoxia-Restraint Animal Model-CHR, Seven-Star, India ;rectal probes, Seven Star, India; Iso-thermex, Columbus Instruments, USA.

\section{Plant Material and preparation of extract}

Plant material with voucher specimen no. CSK HPKV-NAIPSBT-Sp. T1 for Hippophae rhamnoides turkestanica (HRT) was obtained from CSK, Palampur, Himachal Pradesh and its 
extract were prepared using Accelerated Solvent Extractor (ASE) (Sharma et al., 2015). The aqueous extract of HRT was code named as SBT-5.

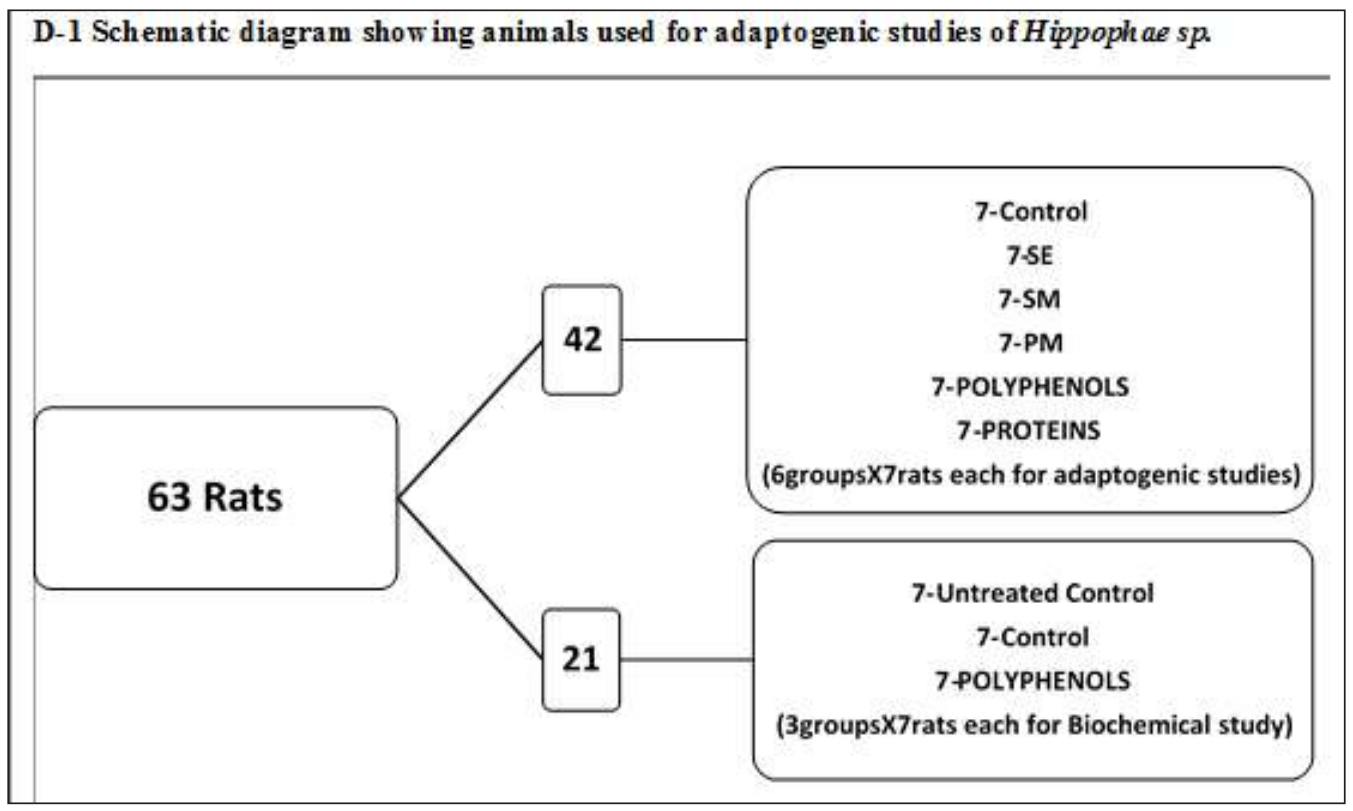

\section{Fractionation of aqueous extract of HRT}

SBT-5 was subjected to following types of fractionation:

\section{Fractionation with solvents of increasing polarity}

1 gram of material was weighed and transferred to a boiling tube. $10 \mathrm{ml}$ of hexane was added and sonicated for 15 minutes at room temperature (RT). The mixture was allowed to settle for 3 hours and then filtered. The same process was repeated with ethyl acetate and methanol. The yield was maximal with methanol and the fraction is coded as PM (i.e. Parallel Methanol) (Mohammad Azmin et al. 2016).

\section{Successive extraction with the same solvents}

1 gram of material was weighed and transferred to a boiling tube. $10 \mathrm{ml}$ of hexane was added and sonicated for 15 minutes at RT. The mixture was allowed to settle for 1 hour and then filtered. The residue was again washed with hexane and then decanted. The same residue was dried and extracted with 10 $\mathrm{ml}$ ethyl acetate, sonicated for 15 minutes. The mixture was allowed to settle then decanted and the residue is again washed with ethyl acetate and after final decantation it was dried. The residue was finally extracted with methanol and processed in the same way as described above. Thus here 2 fractions were obtained. The decant of ethyl acetate was coded as SE (Successive Ethyl acetate) and that of methanol was coded as SM (Successive Methanol). The fractions were concentrated to dryness in water bath (temp. maintained $40^{\circ} \mathrm{C}$ ) for 45 minutes (Roy et al 2018).

\section{HPTLC Analysis}

All the three fractions namely PM, SE and SM were subjected to HPTLC analysis. The mobile phase was Methanol, Chloroform, Ethyl acetate, Toluene and Formic acid in ratio
1.5:1:4.5:3:0.5. $10 \mu \mathrm{l}$ of each fraction was applied on the TLC plate by Linomat sample applicator. The fractions were tested for their adaptogenic potential in CHR as described in later section on adaptogenic potential of fractions.

Out of the three fractions analysed, SM was found to possess maximum adaptogenic activity. Since it was obtained from a polar solvent (methanol) so further functional group separation technique (using TCA) was carried out and two additional fractions were obtained- one being Polyphenolic rich (PRF) and other Proteins rich. These two were also studied in CHR. HPTLC fingerprints for all the five extracts were obtained followed by derivatization with Ninhydrin and Ferric chloride solution.

\section{Experimental design for evaluation of adaptogenic activity}

\section{Experimental animals}

Sprague-Dawley inbred male rats, 12-14 weeks old, weighing $150 \pm 10 \mathrm{gm}$, from the experimental animal facility of the Institute were used for the study. The rats were maintained inside polypropylene cages with free access to standard animal food pellets and water at $22 \pm 1^{\circ} \mathrm{C}$ temperature, $55 \pm 1 \%$ humidity and $12 \mathrm{~h}$ light-dark cycle. The study was approved by the Animal Ethical Committee of our institute in accordance with Committee for the Purpose of Control and Supervision on Experiments on Animals (CPCSEA) of the government of India.

\section{Adaptogenic Potential of Fractions}

The schematic diagram (D-1) shows grouping of animals used for adaptogenic studies of aqueous extract of HRT (SBT$5)$. 
Total 42 animals were used in the adaptogenic study using CHR. This model uses resistance in fall of rectal temperature as a measure of endurance (Ramachandran U et al. 1990). The rats were divided into 6 groups of 7 rats each. Out of the six groups, one group that served as control was administered with distilled water and rest of the five groups were administered with fractions at a dose $25 \mathrm{mg} / \mathrm{kg}$ body weight ( $0.5 \mathrm{ml}$ for $150 \mathrm{gm}$ of rat) 30 minutes prior to exposure in the CHR.The rectal probe was inserted $2 \mathrm{~cm}$ past the rectum of the rat and retained there with the help of adhesive plaster. The rectal temperature of the rats was monitored continuously, every minute by Iso-thermex temperature Recorder. Out of the five, the fraction that induced maximum physiological resistance (as shown by resistance in fall of rectal temperature) in rats to CHR induced hypothermia was further studied for its in vivo potential at tissue level. The results have been compared with those of SBT-5 as described in Sharma et al. 2015.

\section{In Vivo Antioxidant status and stress markers}

To determine mechanism of action,21 overnight fasted rats (D-1) were used to see the level of ROS, SOD, CAT, LDH, GSH/GSSG and MDA in the samples. The rats were divided into 3 groups of 7 rats each: (i) Untreated rats not exposed in CHR; (ii) Water administered rats i.e. Control and (iii) PRF administered rats at single dose of $25 \mathrm{mg} / \mathrm{kg}$ body weight. In both ii and iii groups oral administrations were done 30 minutes prior to exposure in CHR. The rest is same as described in section on adaptogenic potential of fractions.

\section{Biochemical Assays}

The methodology for biochemical assays are as described in Sharma et al., 2012 and Sharma et al.,2015. It is briefly explained here.

\section{Lipid peroxidation}

The reaction mixture containing TCA (trichloroacetate) and TBA (thiobarbituric acid) along with sample was boiled for 45 min in a boiling water bath. After cooling the supernatant was taken and the optical density (OD) was read at $531 \mathrm{~nm}$ to measure the amount of MDA formed in each of the samples. 1, 1, 3, 3-tetraethoxy propane was used as standard and the results are expressed as $\mu \mathrm{M} /$ (mg protein).

Reduced Glutathione/ oxidizedglutathione (GSH/GSSG) Ratio of reduced glutathione (GSH) and oxidized glutathione (GSSG) was obtained. A standard plot was obtained using $1 \mathrm{mg} / \mathrm{ml} \mathrm{GSH}$ and GSSG respectively and their respective concentrations in samples are extrapolated in $\mathrm{mM} / \mathrm{ml}$ followed by their ratio.

\section{Superoxide Dismutase (SOD)}

The total SOD assay volume $(3.0 \mathrm{ml})$ consisted of Triscacodylatebuffer, nitro blue tetrazolium salt (NBT), TritonX100, water, sample and pyrogallol. A blank was run simultaneously consisting of water instead of sample. Enzyme kinetic activity was recorded at $540 \mathrm{~nm}$ for $3 \mathrm{~min}$ and change in OD per minute ( $\Delta \mathrm{OD}$ ) was used to calculate $\%$ auto-oxidation inhibition to derive SOD units (U). One U of SOD was defined as $50 \%$ inhibition of the auto-oxidation caused by a certain volume of enzyme. The results of SOD activity have been expressed as $\mathrm{U} /(\mathrm{mg} \text { protein })^{-1}$.

\section{Lactate dehydrogenase (LDH)}

Pyruvate buffer, sample and NADH were taken as reaction mixture. The LDH activity was calculated based on oxidation of NADH, using a molar extinction coefficient of $6.22 \times 10^{-}$ ${ }^{3} \mathrm{M}^{-1} \mathrm{~cm}^{-1}$.LDH activity has been expressed as nmol NADH oxidized per minute per mg protein [ $\mathrm{nmol} \mathrm{min}^{-1}$ (mg protein) $\left.{ }^{1}\right]$.

\section{Catalase (CAT)}

The reaction mixture consisted of buffer substrate and sample. Change in absorbance was recorded for 150s(every $15 \mathrm{~s})$ at $240 \mathrm{~nm}$. Catalase activity was calculated using an extinction coefficient of $0.041 \mathrm{~cm}(\mathrm{mmol})^{-1}$ and expressed as mmol $\mathrm{H}_{2} \mathrm{O}_{2}$ consumed per minute per mg of protein [mmol $\min ^{-1}$ (mg protein $\left.)^{-1}\right]$.

\section{Total protein estimation}

Copper reagent was added to $0.25 \mathrm{ml}$ of sample. Tubes were incubated for $15 \mathrm{~min}$ at $37^{\circ} \mathrm{C}$. Folin-Ciocalteu reagent (FCR, $1 \mathrm{~N}, 0.25 \mathrm{ml}$ ) was added and tubes were again incubatedat $37^{\circ} \mathrm{C}$ for $30 \mathrm{~min}$. A standard graph was prepared using bovine serum albumin stock solution. Absorbance was read at 750 $\mathrm{nm}$. The protein concentration in the test samples were extrapolated from the standard graph and expressed as $\mathrm{mg} \mathrm{ml}^{-}$ 1.

\section{Reactive Oxygen Species (ROS)}

Sample along with 2, 7-Dichloro-dihydro-fluorescein diacetate (DCFHDA) was incubated at room temperature for 15-45 minutes depending upon sample. Fluorescence was measured with excitation wavelength $485 \mathrm{~nm}$ and emission wavelength $530 \mathrm{~nm}$ against blank.

\section{Immune response generated by fractions}

Bioefficacy of fractions was evaluated in vivo using Balb/c mice (5-6 weeks old, weighing \pm 25 grams) with one weak antigen Ovalbumin (ova) (Sigma) and one strong antigen Tetanus Toxoid (TT) from Kasauli, India, in terms of antibody titres generated against these antigens. The mice were primed with the formulations of antigen and fractions (10 $\mu$ g dose/animal) on the day 1 , followed by a booster on the day 21. On day 28, animals were bled for antibody (IgG) estimation by indirect ELISA. Each of the said doses was administered to the animals through intraperitoneal route. $2 \%$ Aluminum Hydroxide (Alum) and whole leaf extract of SBT (Alc-SBT) was used as positive controls (Tanwar et al., 2019).

\section{Estimation of Immunoglobulin titers}

For estimation of antibody titers, Microtitre plates, (Greiner, USA), were coated with OVA $20 \mu \mathrm{g} / \mathrm{ml}$ in $0.01 \mathrm{M}$ PBS, $\mathrm{pH}$ $7.2)$ and TT $(0.5 \mu \mathrm{g} / \mathrm{ml}$ in $0.01 \mathrm{M}$ PBS, $\mathrm{pH} 7.2)$ for 24 hours at $4^{\circ} \mathrm{C}$. All the incubations were carried out at $37^{\circ} \mathrm{C}$ with gentle 
shaking and the plates were washed three times with $0.01 \%$ Tween20 $\left(\mathrm{PBST}_{20}\right)$ between the incubations. After thorough washing, plates were incubated for one hour with $1 \%$ BSA as a blocking solution, for avoiding any non-specific binding. Following thorough washing, plates were incubated for two hours with 1:10000 dilution of sera samples from immunized mice. Rabbit anti mouse IgG conjugated to horseradish peroxidase (HRP) (Sigma, Denmark), diluted in $\mathrm{PBST}_{20}$ (1:4000 IgG) was added to the wells as secondary antibody. The enzyme reaction was visualized by incubation with Orthophenylene diamine (OPD) (Sigma, USA) substrate in $(0.1 \mathrm{M})$ citrate phosphate buffer with $\mathrm{H}_{2} \mathrm{O}_{2}$ (Sigma) as an oxidizing agent. The reaction was stopped after $10 \mathrm{~min}$ by addition of $50 \mu \mathrm{l}$ of $2 \mathrm{~N} \mathrm{H}_{2} \mathrm{SO}_{4}$ (MP Biochemicals, USA) and the absorbance was measured at $450 \mathrm{~nm}$ in an ELISA reader (BioTek Instruments, USA).

\section{Statistical analysis}

The results were analysed by one-way ANOVA (analysis of variance) with Sidak's Multiple Comparisons Test using Graph Pad Prism v.6. Differences were considered to be significant when the p values were $<0.05$.

\section{Results}

HPTLC profiling of fractions of aqueous extract of HRT Fig.1A shows TLC profiling of the three fractions, SE, PM and SM.Constituents'bands are seen in Histogram in Fig. 1B.

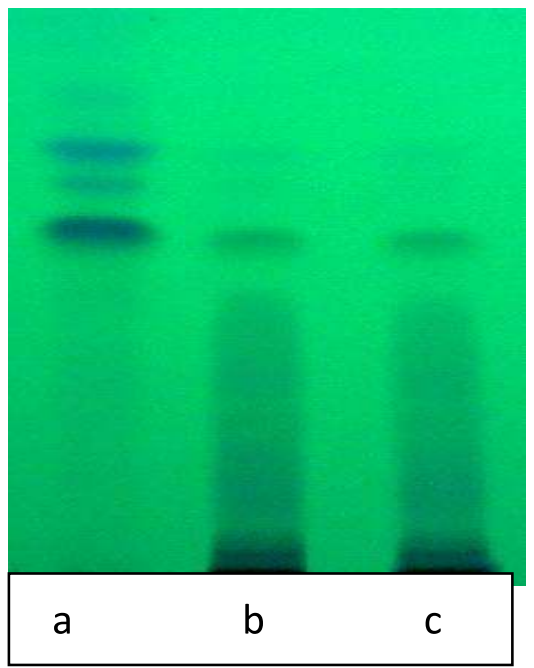

Figure1A:TLC photograph (under 254nm) of the Aqueous Extract

Track a-Successive ethyl acetate extract (SE)

Track b-Parallel methanol extract (PM)

Track c-Successive methanol extract (SM)

HPTLC chromatograms for SE, PM and SM are shown in Fig 2A-2C with respectively 10,10 and 11 unidentified components. The overall spectral scans (Fig.2D) shows overlapping peaks which state the possibility of presence of some common components in the three fractions. Fig. 3A-3B depict ninhydrin-derivatized TLC profiling of the fractions.

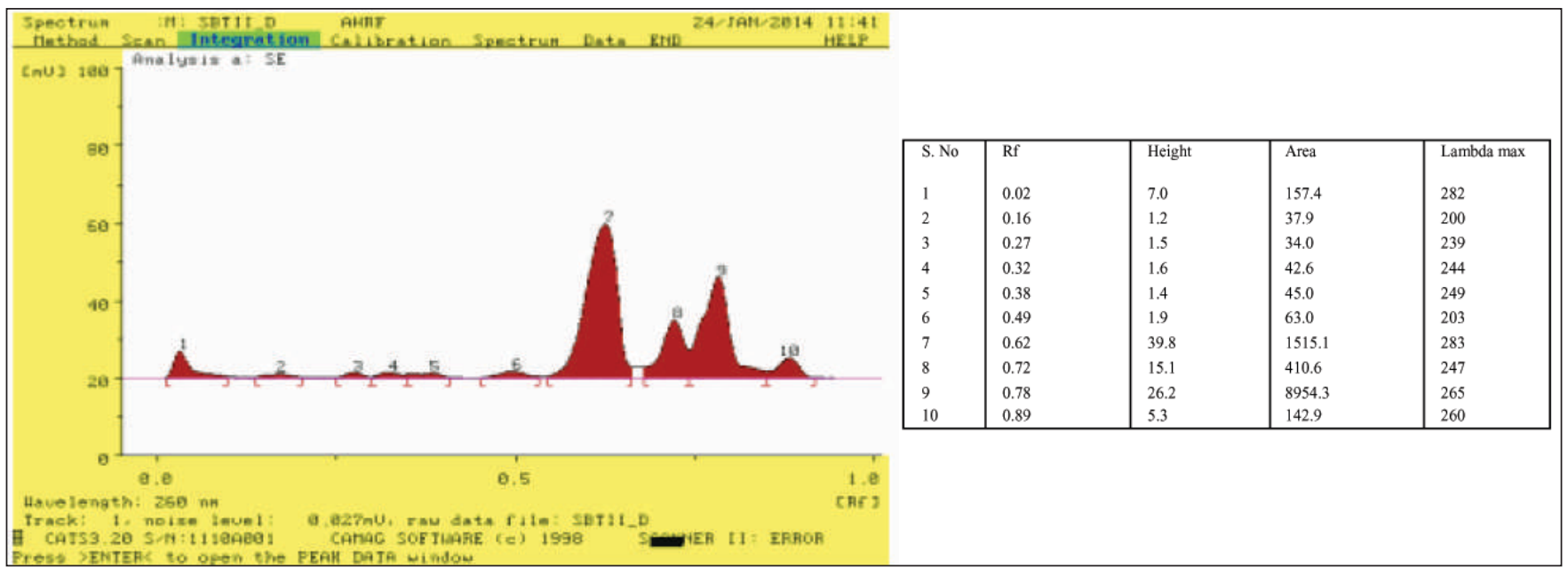

Fig. 2A: HPTLC chromatogram for Successive Ethyl acetate extracts (SE) 


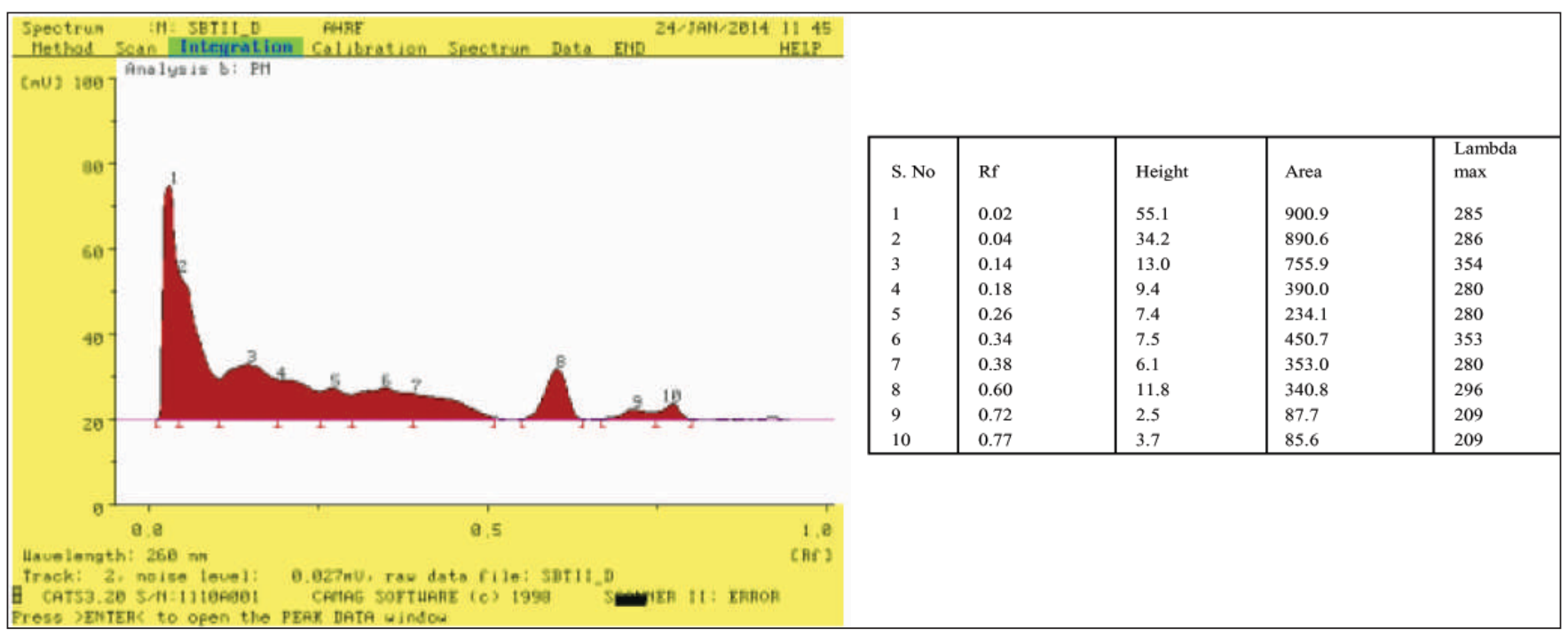

Fig. 2 B: HPTLC chromatogram for Parallel Methanol extracts (PM).

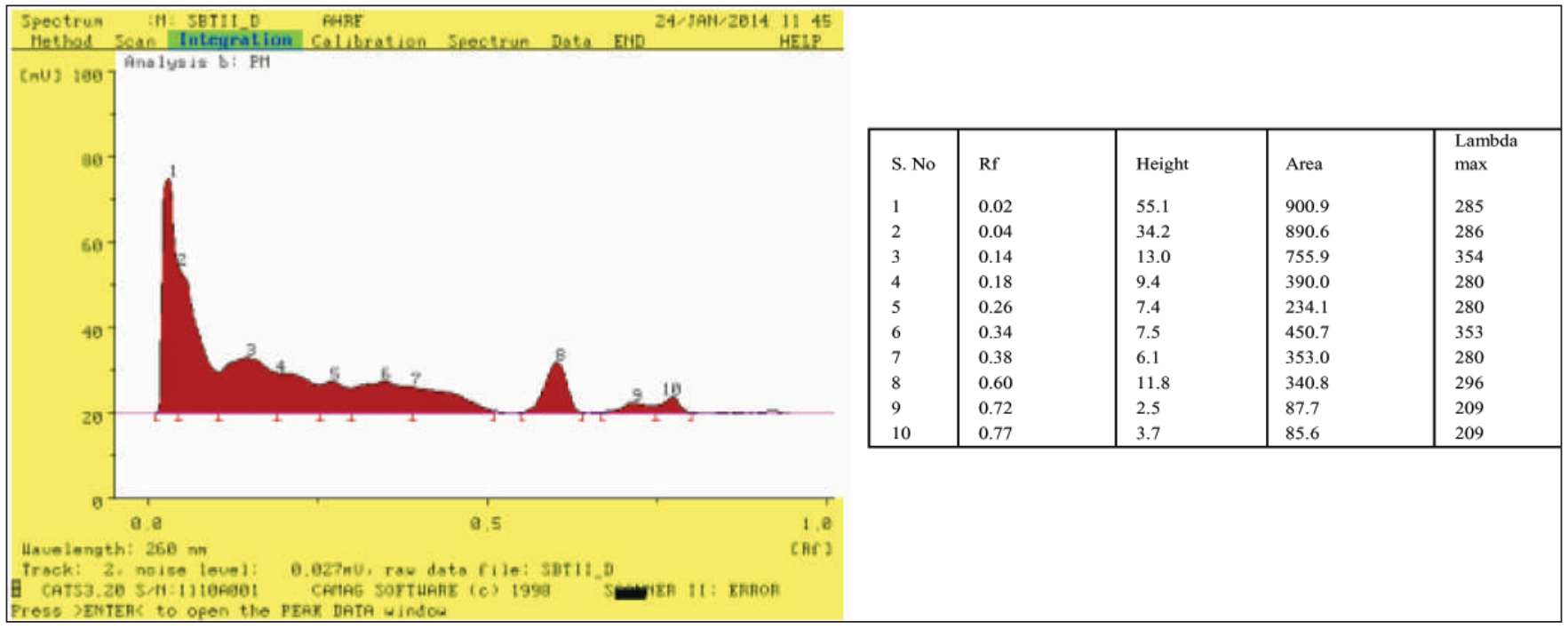

Fig. 2 C: HPTLC chromatogram for Successive Methanol extracts (SM).

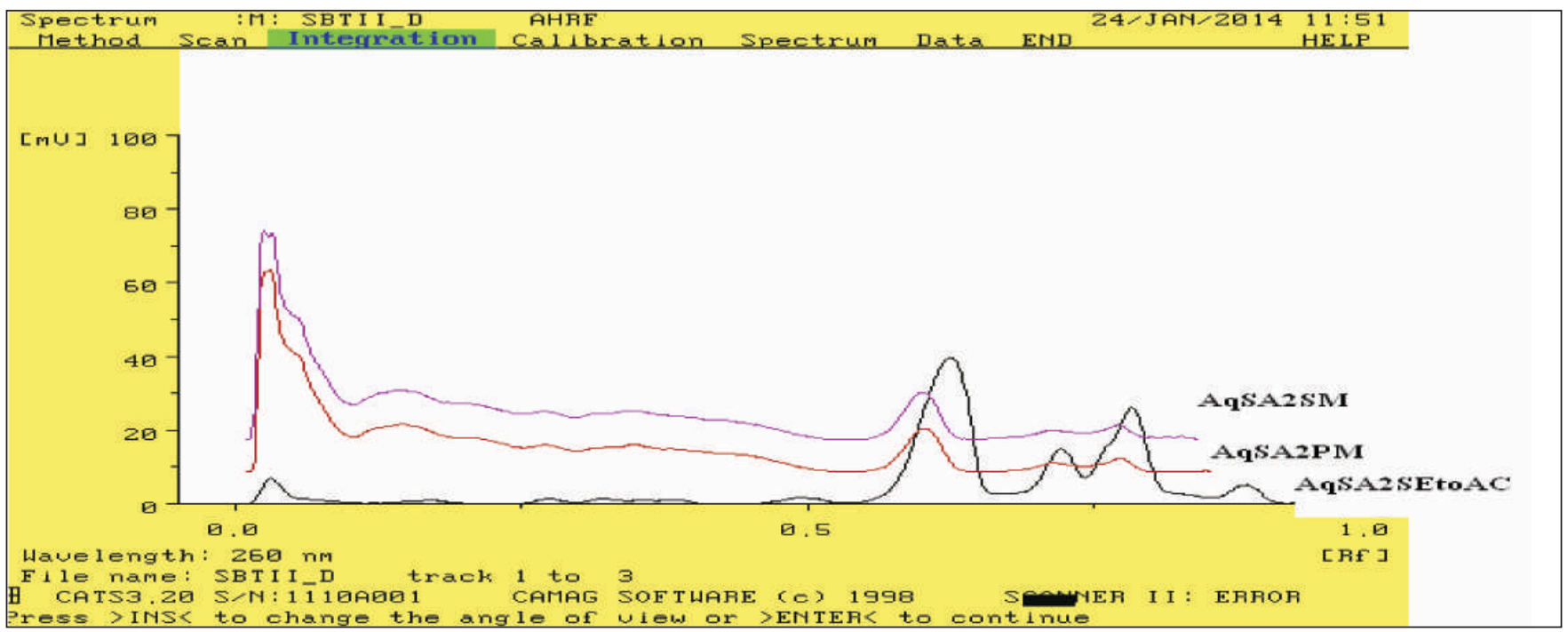

Fig. 2 D: Over all chromatograms. 
Histogram of the extract after derivatization shows the presence of proteins in the three fractions.

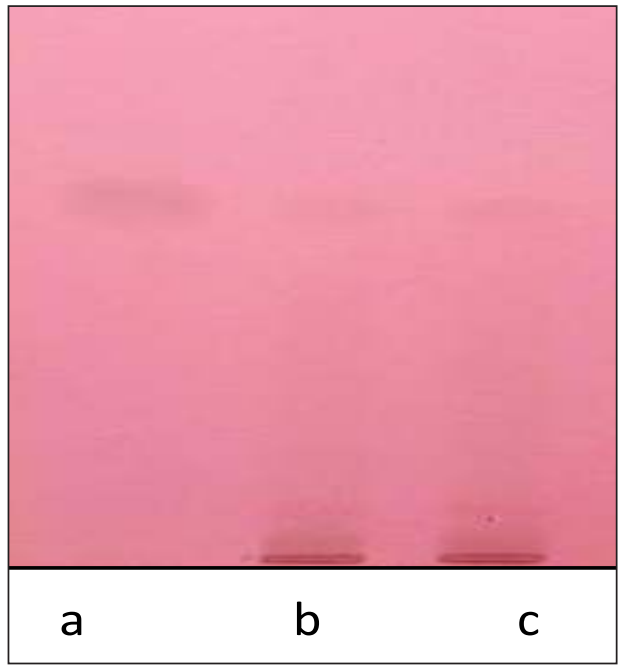

Figure 3A:TLC photograph (Ninhydrinderivatized for Protein) of the Aqueous Extract

Track a - Successive ethyl acetate extract (AqSA2SE)

Trackb - Parallel methanol extract (AqSA2PM)

Track c - Successive methanol extract (AqSA2SM)

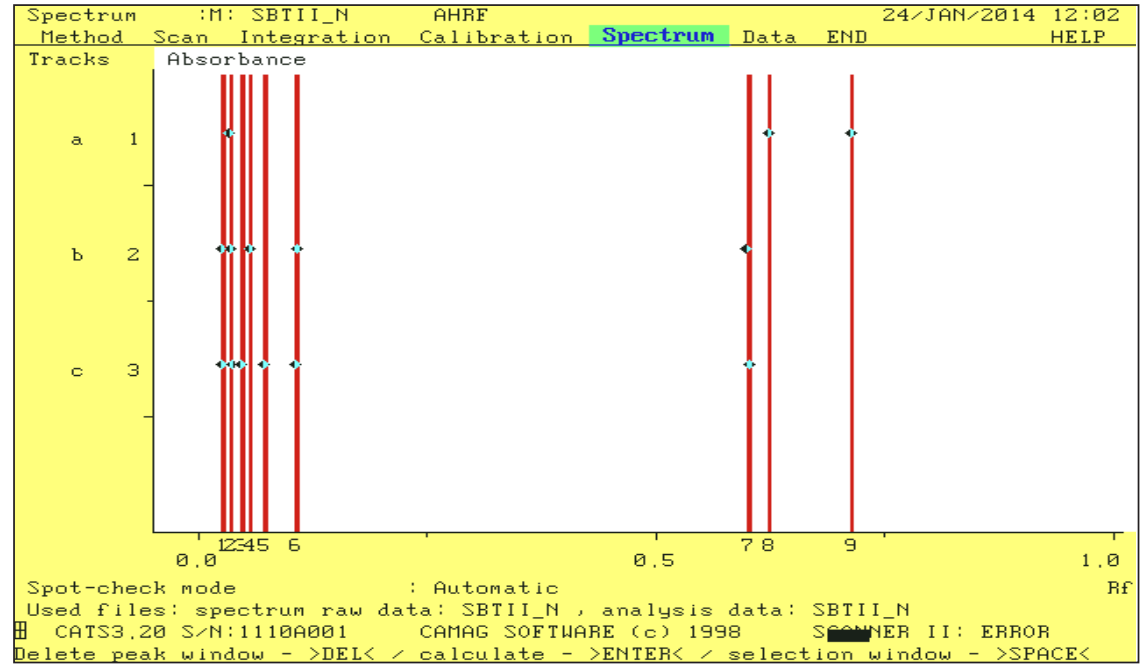

Figure 3B:Histogram for Water Extract after ninhydrin derivatization
Quantitatively 3, 5 and 6 different proteins are identified in chromatograms of the fractions SE, PM and SM respectively

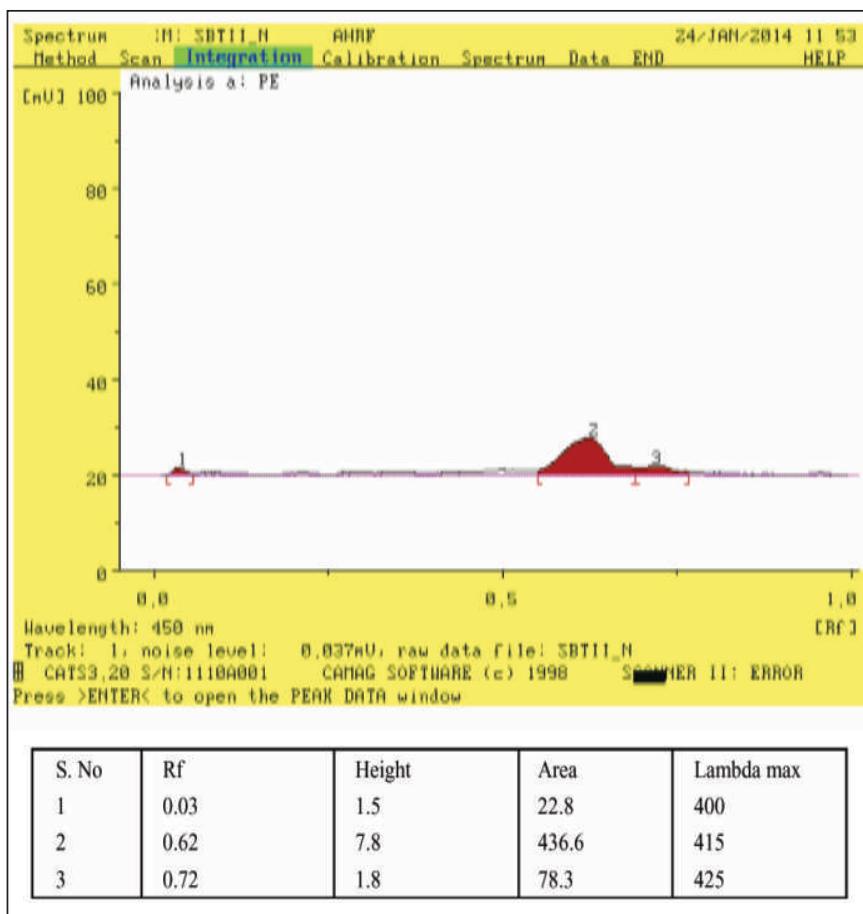

Fig. 4A: HPTLC chromatogram for Sucessive Ethyl aetate extract (AqSA2SE) after derivatised with Ninhydrin reagent.
(Fig. 4A-4C). The overall spectral scan shows possibility of common proteins in the three fractions (Fig. 4D).

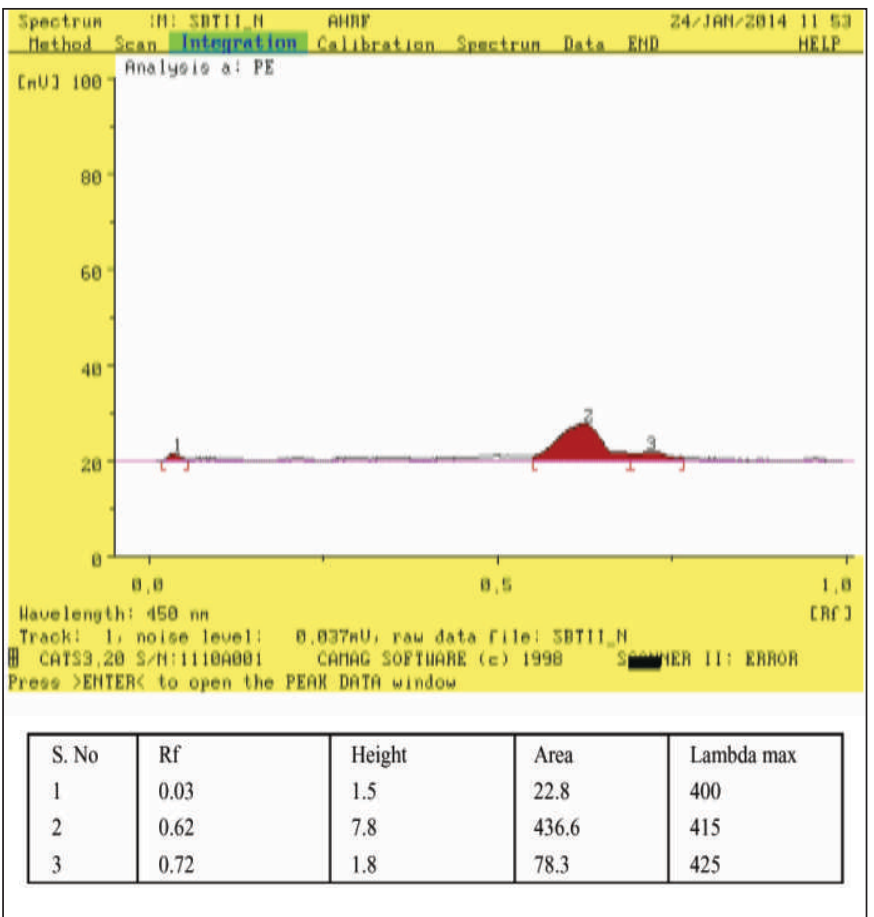

Fig. 4B: HPTLC chromatogram for Parallel Methanol extract (AgSA2PM) after derivatization with Ninhydrin reagent. 


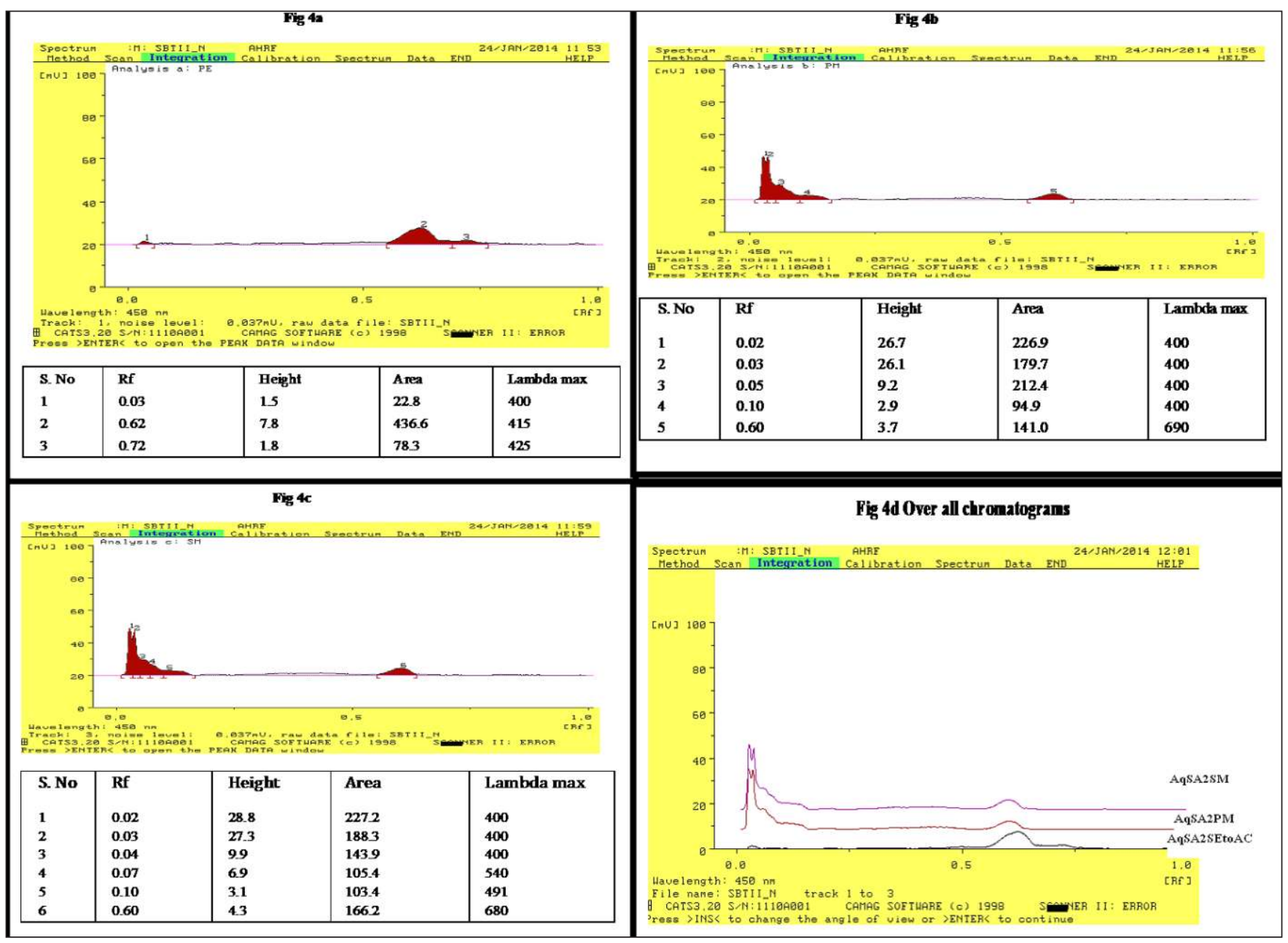

TLC profiling in Fig 5A-5B depicts bands for polyphenolic rich compounds after derivatization with Ferric chloride solution. Fig 5B shows the Histogram of derivatized HPTLC plate for the constituting poly phenols in the three fractions.
Respectively 5, 2 and 3 phenolic rich compoundsare identified in SE, PM and SM (Fig. 6A-6C). As such no overlapping peaks has been identified (Fig 6D).

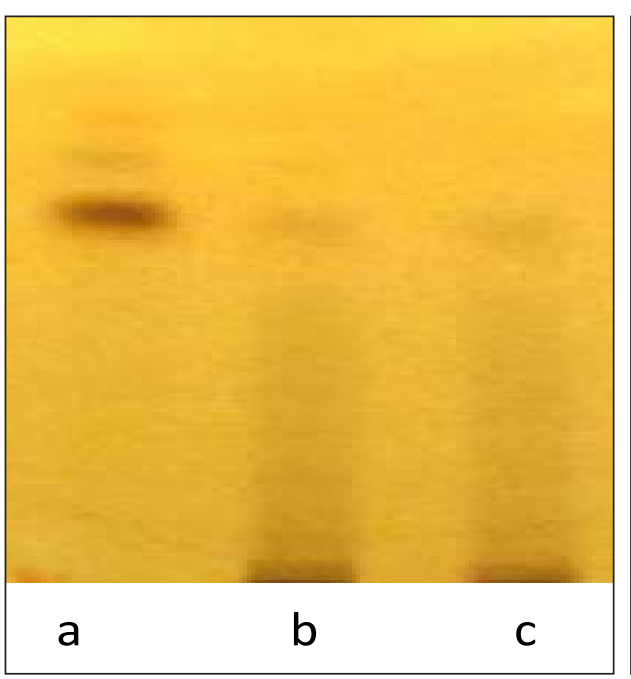

Figure 5A:TLC photograph (Ferric chloride derivatization for Poly Phenol) Track a - Successive ethyl acetate extract (AqSA2SE)

Trackb - Parallel methanol extract (AqSA2PM)

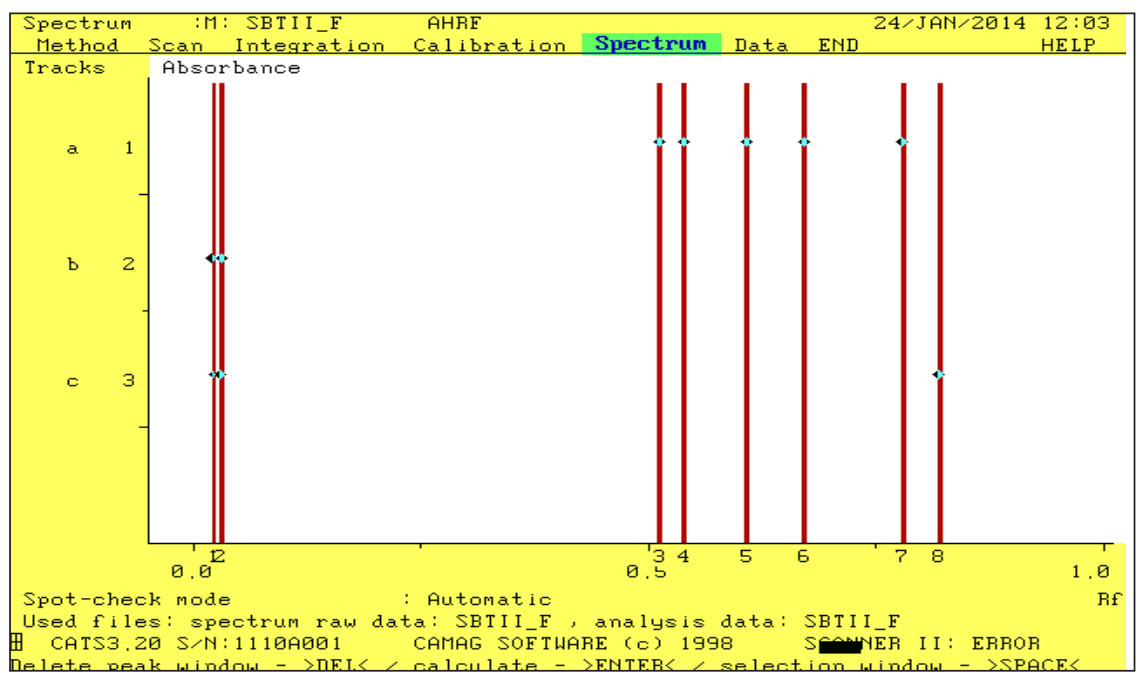

Figure 5B: Histogram for Water extracts derivatization with Ferric chloride solution 

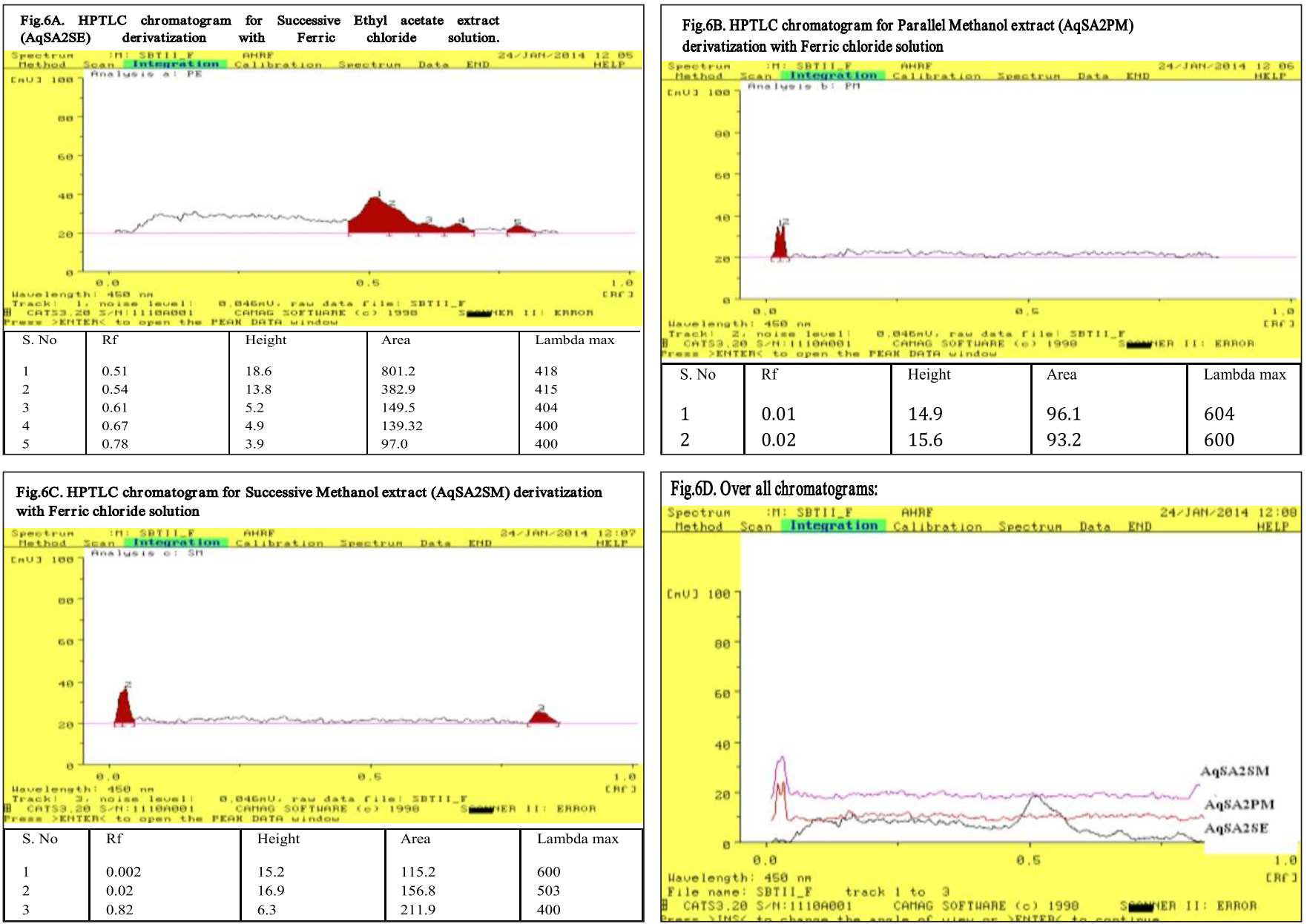

Adaptogenic activity of seabuckthorn fractions

The adaptogenic potential of the five fractions of SBT- 5 was studied for their adaptogenic potential using CHR animal model. The results were compared both with control and SBT-5 (Fig.7). SBT-5 was given as $100 \mathrm{mg} / \mathrm{kg}$ body weight (Sharma et al. 2015)p.o whereas the fractions were given as $25 \mathrm{mg} / \mathrm{kg}$. body weight.

As given in Table-1, compared to control, SE showed $43.48 \%$ resistance against CHR induced hypothermia and a faster recovery by $10.43 \%$. SM showed a maximum, $69.57 \%$ resistance against CHR induced stress and the time taken to attain $\mathrm{T}_{\text {rec }} 37^{\circ} \mathrm{C}$ reduced by $9.20 \%$. An increase of $34.78 \%$ and $9.20 \%$ in time taken to attain $\mathrm{T}_{\text {rec }} 23^{\circ} \mathrm{C}$ and $\mathrm{T}_{\text {rec }} 37^{\circ} \mathrm{C}$ respectively was observed for PM. The Polyphenolic rich fraction (PRF) of SBT-5 showed the maximum adaptogenic potential. It showed

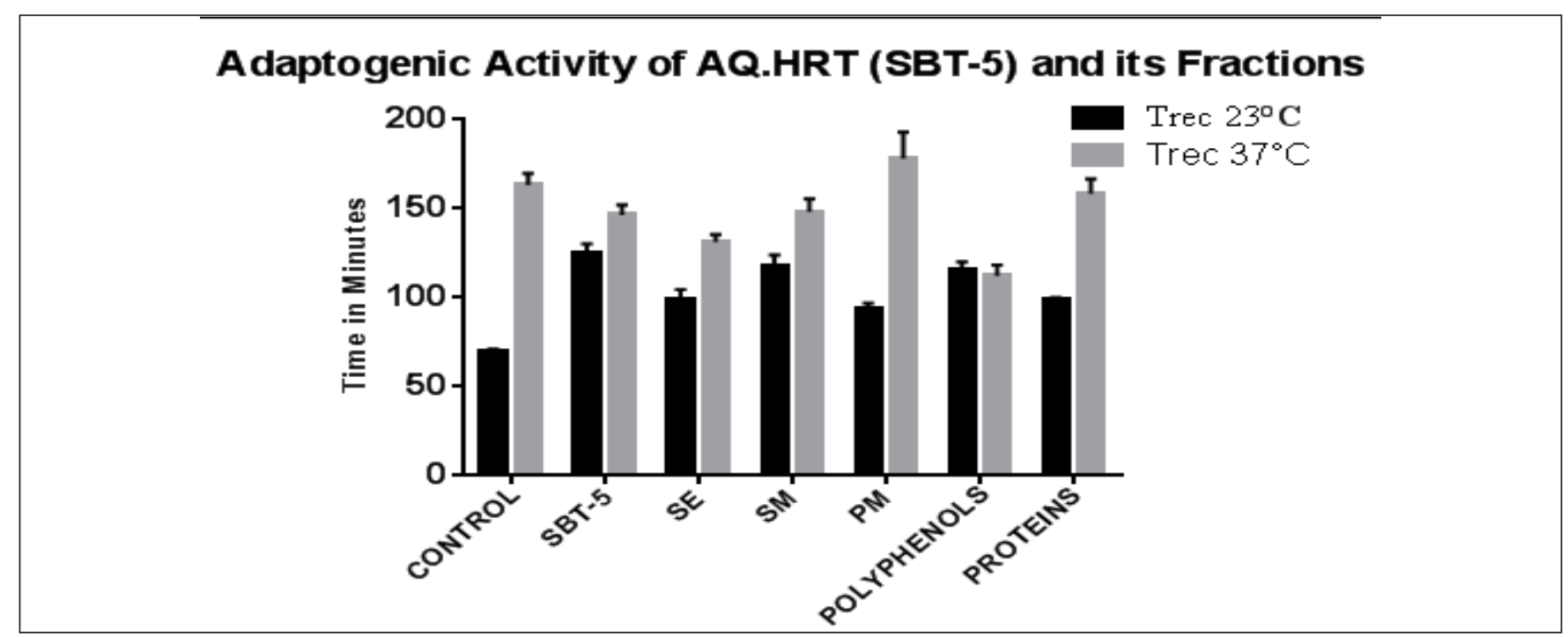

Figure 7:Adaptogenic activity of Seabuckthorn Fractions with comparison to Control \& SBT-5. 
a hypothermic resistance of $66.67 \%$ and a faster recovery from hypothermia by $31.29 \%$. The resistance of $42.03 \%$ from CHR induced hypothermia was seen in Proteins fraction whereas the recovery was fastened only by $3.07 \%$. In all these results the \%change in time taken to attain $\mathrm{T}_{\text {rec }} 23^{\circ} \mathrm{C}$ was significant whereas the \%change in time taken to attain $\mathrm{T}_{\text {rec }} 37^{\circ} \mathrm{C}$ was nonsignificant except in PRF.

The same results of the fractions as detailed above when compared to SBT-5, they were found to be comparable for
SM and PRF where a non-significant change of $6.40 \%$ and 8\% were observed for resistance against CHR induced hypothermia whereas for SM the \% change from recovery from hypothermia was a non-significant $1.37 \%$ only, it was significantly high for PRF at 23.29\%. For the rest of the fractions the resistance from CHR induced hypothermia was 20.08, 25.6 and 21.6\% respectively for SE, PM and Proteins and the delay in the time taken for recovery were 10.27, 21.92 and $8.22 \%$ respectively.

Table-1: Adaptogenic activity* of seabuckthorn leaf extract (SBT-5) and its five fractions after single dose (p.o.) of 100 and $25 \mathrm{mg} / \mathrm{Kg}$. body weight respectively.

\begin{tabular}{|l|c|c|}
\hline Extracts & T1 $^{{ }^{*}}$ & T2 $^{\mathbf{b}}$ \\
\hline CONTROL & $69 \pm 1.88$ & $163 \pm 6.64$ \\
\hline SBT-5 & $125 \pm 4.97^{*}$ & $146 \pm 5.89$ \\
\hline SBT SA II-SE & $99 \pm 9.02$ & $131 \pm 4.17$ \\
\hline SBT SA II-SM & $117 \pm 6.67$ & $148 \pm 7.27$ \\
\hline SBT SA II-PM & $93 \pm 3.52$ & $178 \pm 14.83$ \\
\hline CARS-II-POLYPHENOLS & $115 \pm 4.67$ & $112 \pm 6.02$ \\
\hline CARS-II-POLYPHENOLS & $115 \pm 4.67$ & $112 \pm 6.02$ \\
\hline CARS-II-PROTEINS & $98 \pm 1.67$ & $158 \pm 8.34$ \\
\hline
\end{tabular}

*Values are mean $\pm \mathrm{SE}$ of six rats in each group; $\mathrm{T}^{\mathrm{a}}$ : time taken (in min) to attain $\mathrm{Trec} 23^{\circ} \mathrm{C}$; $\mathrm{T}^{\mathrm{b}}$ : time taken (in min) to attain Trec $37^{\circ} \mathrm{C} ; * \mathrm{P}<0.05$, compared with respective group of control rats.

Antioxidative status and stress markers

The results on antioxidant status and stress markers in the blood samples of rats are shown in Fig.8 (a-f).

In blood samples there was $171 \%$ increase in the fold change of ROS activity in exposed control rats as compared to unexposed control. However, the levels reduced by a nonsignificant percent of $18 \%$ for PRF. The SOD levels were increased by $119 \%$ in exposed control rats as compared to unexposed control. However, the levels were significantly reduced by $51 \%$ for the fraction as compared to exposed control. After administration of SBT-1 and 5the level of CAT

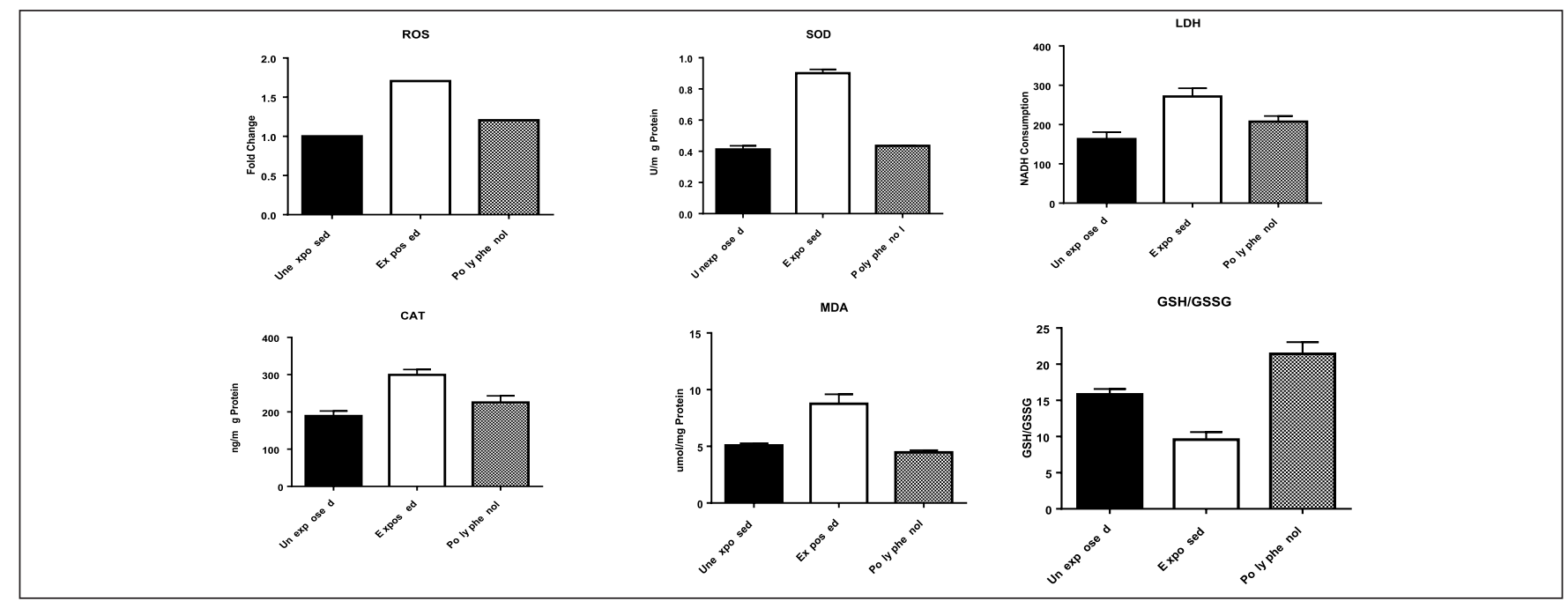

Figure 8: (A-F)Effect of polyphenols fraction supplementation on antioxidative stress parameters in Blood. 
that enhanced by $58 \%$ in exposed control rats as compared to unexposed control, reduced by $25 \%$ in both the cases in comparison to exposed control. The LDH level in exposed control rats increased by $66 \%$ in comparison to unexposed control whereas the reduction as compared to control exposed for SBT-5 was significant 24\%. Much protective effect against generation of MDA was seen as PRF significantly reduced the levels by $49 \%$ comparison to exposed control rats. The mean ratio of GSH/GSSG was significantly decreased during CHR exposure (40\%) in comparison to unexposed control. Treatment with PRF restored the GSH/GSSG ratio. The trend of antioxidative and stress parameters in case of muscles is given in Fig.9 (a-f).

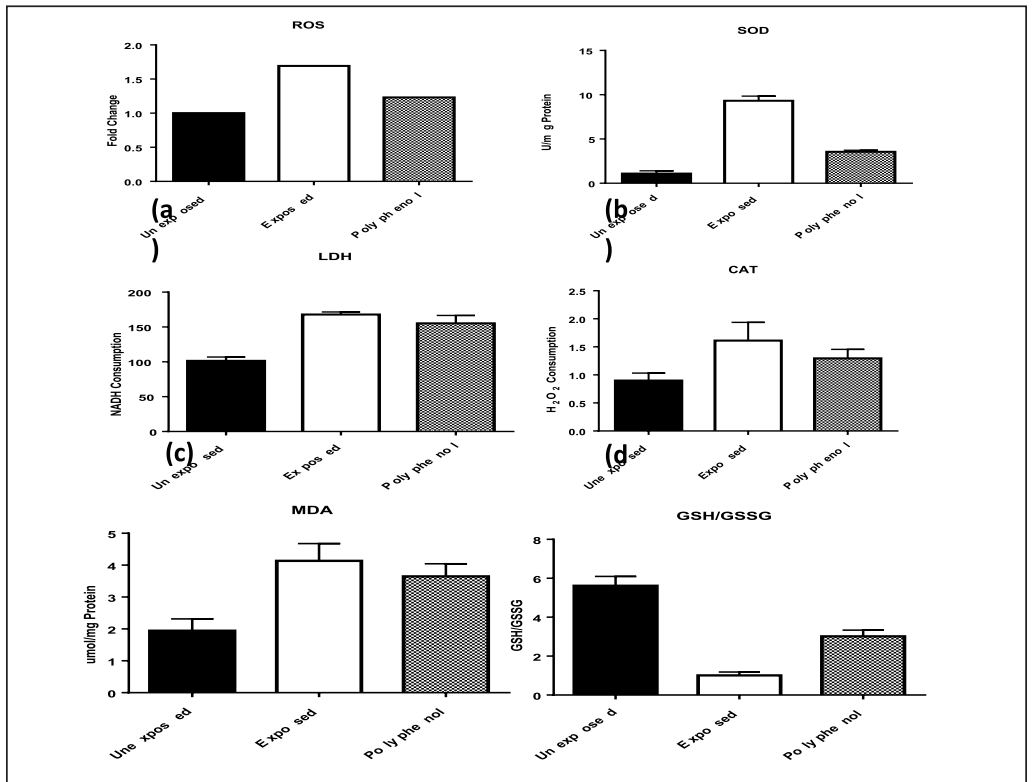

Figure 9 (a-f):Effect of Polyphenolic fraction supplementation on antioxidative stress parameters in Muscle.

Exposure to CHR led to an enhanced oxidative stress as evident by increased ROS, SOD and CAT levels in the exposed control rats. Further supplementation with PRF significantly ameliorated the oxidative stress. The SOD levels that were increased in exposed control rats as compared to unexposed control significantly reduced by $62 \%$ after administration of the fraction as compared to exposed control. The levels of CAT that were increased by $79 \%$ after exposure in control rats reduced by $20 \%$ after the administration of the fraction. CHR induced increase (67\%) in LDH levels in muscles sample were lowered significantly by the fraction (24\% decrease). Further the enhanced MDA levels during CHR exposure were decreased nonsignificantly by $12 \%$.Fig.10 (a-f) shows results on antioxidant status and stress markers in the heart samples.

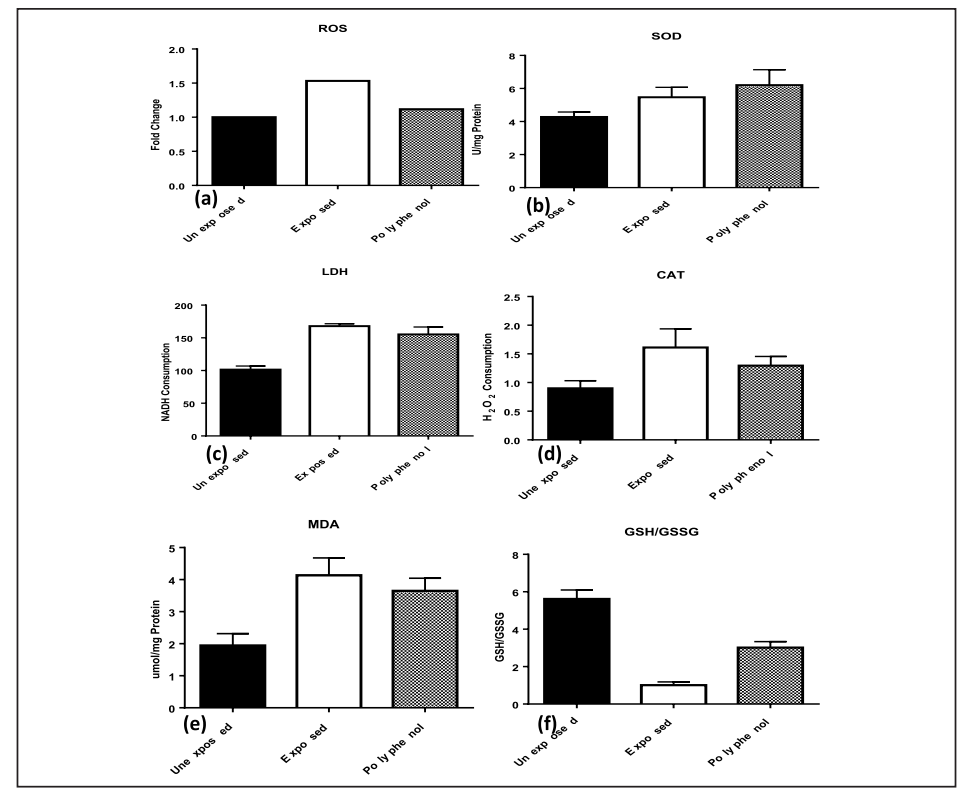

Figure 10 (a-f):Effect of Polyphenolic fraction supplementation on antioxidative stress parameters in Heart. 
Heart samples when analysed for the generation of ROS under multiple stress showed 53\% increase in control exposed rats as compared to unexposed control. The supplementation of PRF reduced the generation of reactive oxygen (ROS) by $12 \%$ as compared to exposed control. There was an increase of $45 \%$ in the levels of Superoxide dismutase (SOD) on attaining $\mathrm{T}_{\text {rec }} 23^{\circ} \mathrm{C}$ in exposed control rats versus unexposed control. This increase reduced by $12 \%$ after administration with PRF. In the fraction treated rats the value of CAT that increased by $109 \%$ in exposed control rats reduced significantly by $43 \%$. In case of LDH the observed increase of significant $52 \%$ in exposed control rats in comparison to unexposed control decreased by $19 \%$ after administration with PRF. The MDA level in exposed control rats increased by $120 \%$ in comparison to unexposed control whereas the reduction as compared to control exposed for the fraction was only $3 \%$. There was $12 \%$ decrease in the ratio of GSH/GSSG which improved by $79 \%$ as compared to exposed control rats after oral supplementation of the fraction.

\section{Immune response generated by fractions}

The initiation of immune response generated by the fractions, SE, PM and SM was measured through indirect Elisa. The result indicates that $\mathrm{SM}$ is showing $74 \%$ increment in TT specific wIgG titers whereas SE showed only $60 \%$ and PM showed 40\% augmentation when compared with TT alone group. Similarly, when compared the immunogenic capabilities of SM, SE and PM with Ova, it was observed that SM exhibited 176\%, SE showed 60.5\% and PM revealed $67.6 \%$ enrichment in Ova specific immune response generated by the fractions when compared with Ova alone group. The fractions alone did not generate any significant immune response. There was approximately 3\% increment in the immune response generated by the fractions (Table 1) (Singh et al. 2017).

Table-2: Comparison of immune response of different fractions of SBT-5 with Ova and TT antigens.

\begin{tabular}{|l|c|c|c|}
\hline Name of Fraction & Alone & Ova & TT \\
\hline & - & $1 \pm 0.02$ & $7 \pm 0.019$ \\
\hline Successive Methanol (SM) & $2.65 \pm 0.09$ & $176.47 \pm 43.23$ & $44.66 \pm 21.45$ \\
\hline Parallel Methanol (PM) & $00 \pm 0.00$ & $67.61 \pm 8.75$ & $60.47 \pm 8.67$ \\
\hline Successive Ethyl acetate (SE) & $2.5 \pm 0.06$ & $60.56 \pm 9.67$ & 14.67 \\
\hline
\end{tabular}

\section{Discussion}

Modern analytical techniques have provided opportunity for the researchers to identify and separate active plant components which are particularly of some importance. Although the nature of plant components is very complicated but it has never deterred the quest to classify active constituents of herbal extracts. Our target was very specific. We have already established the antioxidant and adaptogenic potential of SBT-5 (Sharma et al. 2015).Our aim was to identify its active fraction.

HPTLC is a suitable method for estimation of chemical constituents present in plants materialswith minimum sample clean up requirement (Patil et al. 2012 ; Rakesh et al.2009).HPTLC fingerprinting identifies 3 proteins and 2 polyphenols in SM, the fraction that has shown better adaptogenic potential as compared to SE and PM at a four times lower dose.

SM at a dose of $1 \mu \mathrm{g} /$ animal shows significantwIgG titers with the strong antigen TT (Gupta and Siber 1994) as well as weak antigen Ova, when tested in vivo. Ovais the major protein constituent of chicken egg whites (Sun, 2006). It is widely used as an antigen for immunization research. Enhancement of Ova specific wIgG by SM indicates remarkable potential of this fraction. TT generated immune response is also heightened by SM.
Therefore, the immunomodulatory activity of SM fraction derived from Seabuckthorn leaves demonstrates better outcomes with TT and Ova at a very low dose. This also indicates that the extracts and its major constituents have the potential to be developed into agents for the treatment of a variety of disorders including inflammation (Tanwar et al. 2018).

Both SM and PRF show comparable adaptogenic potentials and later also significantly reduce the recovery time from hypothermia. Thus, phenols might be playing significant role in recovery from CHR generated multiple stresses. Recently polyphenols have been associated with anti-inflammatory, antioxidant, immunomodulatory, and apoptotic properties (Kaulmann et al. 2016). The dietary intake of polyphenols could be as high as $1 \mathrm{~g}$ /day, which is much higher than that of all other classes of phytochemicals and known dietary antioxidants (Manach C, 2004; Scalbert and Williamson 2000; Wisnuwardani et al. 2019). Polyphenols-rich plants and their extracts ameliorate the severity and progression of Inflammatory Bowel Disease (Michielan andD'Incà2015; Rahman et al. 2018).Previous study also proved potent antioxidant and antibacterial properties of polyphenolic rich compounds(Yogendra et al. 2013; Bouarab-Chibaneet al. 2019). These compounds could also prevent oxidative damage in the liver (Maheshwari et al. 2011). Phenolic compounds such as flavonoids, phenolic acids, diterpenes 
and tannins have received attention for their high antioxidative activity (Bertelli et al. 2015; Dibanda et al. 2020). Bioassay-guided fractionation of extracts obtained from one of the other high altitude plant Rhodiola has shown that the active components are mainly phenylethanolic derivatives and phenylpropanoids (Sharma and Misra, 2018). Flavonoid rich fraction of HR was found to be safe and effective for radio protection (Chawla et al. 2007). Our own studied also demonstrated significant amounts of total phenol and flavonoids content in SBT-5 with identification and quantification of Gallic acid which is a potent antioxidant (Sharma et al. 2015).

Thus, it could also be suggested that the polyphenols contributes significantly towards the anti-stress adaptogenic potential of SBT-5, SM and PRFwhen studied using CHR animal model.Under multiple stressful conditions of CHR oxidative stress is generated. This study incorporates those parameters that give us a purview of oxidative damage, like ROS for oxidative stress, MDA, a marker for lipid peroxidation and LDH, a marker of stress induced membrane damage and important antioxidants like SOD, CAT and GSH. PRF possesses great potential in terms of oxidative stress protection than the crude extract as a whole because it had shown comparable results at four times lower dose. This may be attributed to the fact that flavonoids can directly scavenge molecular species of active oxygen: $\mathrm{O}_{2}$-superoxide, $\mathrm{H}_{2} \mathrm{O}_{2}$ hydrogen peroxide, OH-hydroxyl radical, ${ }^{1} \mathrm{O}$-singlet oxygen or peroxyl radical. Their antioxidant action resides mainly in their ability to donate electrons or hydrogen atoms (Borges Bubols et al. 2013; Sarian and Williamson 2017).

\section{Conclusion}

SM has shown its potential both as an adaptogen as well as immunomodulator. Its adaptogenic potential is comparable to PRF but both fractions are better than SBT- 5 as they have shown their activities at four times lower dose. In addition, Polyphenols fraction also fastens recovery from CHR induced hypothermia.This study gives us a lead that PRF plays important role in adaptogenic and antioxidant properties.

\section{Conflict of Interest}

The authors declare that they have no conflicts of interest concerning this article.

\section{Acknowledgements}

We are grateful to Dr. Srinivasan Narsimhan from Asthagiri Herbal Research Foundation, Chennai, Tamil Nadu, India for help rendered in preparing SBT fractions. This study was supported and funded by the Defence Research and Development Organization, Ministry of Defence, Government of India. We are especially thankful to Director, DIPAS for constant support and encouragement.

\section{References}

1. Aggrawal A, Tewari S, Shivakumar S, Ilango K, Singh RG, Dubey GP (2014) In: Seabuckthorn
(Hippophae L.): A multipurpose wonder plant (Ed: Virendra Singh). New Delhi, India. 4:465-78.

2. Bertelli D, Maietti A, Papotti G, Tedeschi P, Bonetti G, Graziosi R, Brandolini V, Plessi M (2015) Antioxidant activity, phenolic compounds, and NMR characterization of balsamic and traditional balsamic vinegar of Modena. Food Anal methods. 8:371-379.

3. Borges Bubols G, da Rocha Vianna D, MedinaRemon A, von Poser G, Maria Lamuela-Raventos R, Lucia Eifler-Lima V, Cristina Garcia S (2013) The antioxidant activity of coumarins and flavonoids. Mini Rev Med Chem.13:318-34.

4. Bouarab-Chibane L, Forquet V, Lantéri P, Clément Y, Léonard-Akkari L, Oulahal N, Degraeve P, Bordes C (2019) Antibacterial properties of polyphenols: characterization and QSAR (Quantitative structure-activity relationship) models. FrontMicrobiol.https://doi.org/10.3389/fmicb.2019.00 829.

5. Chawla R, Arora R, Singh S, Sagar RK, Sharma RK, Kumar R, Sharma A, Gupta ML, Singh S, Prasad J, Khan HA, Swaroop A, Sinha AK, Gupta AK, Tripathi RP, Ahuja PS (2007) Radioprotective and antioxidant activity of fractionated extracts of berries of Hippophaerhamnoides. J Med Food. 10: 101-09.

6. Dibanda RF, Akdowa EP, Tongwa QM (2020) Effect of microwave blanching on antioxidant activity, phenolic compounds and browning behaviour of some fruit peelings. Food Chem..https://doi.org/ 10.1016/j.foodchem. 2019.125308.

7. Geetha S, SaiRam M, Mongia SS, Singh V, Ilvazhagan G, Sawhney RC (2003) Evalation of antioxidant activity of leaf extract of seabuckthorn (Hippophaerhamnoides L.) on chromium (VI) induced oxidative stress in albino rats. J Ethnopharmacol 87:247-251.

8. Gupta A, Kumar R, Pal, K, Banerjee PK, Sawhney RC (2005) A preclinical study of the effects of seabuckthorn (Hippophaerhamnoides L.) leaf extract on cutaneous wound healing in albino rats. Int J. Low Extrem Wounds. 4:88-92.

9. Gupta RK, Siber GR (1994) Comparative analysis of tetanus antitoxin titers of sera from immunized mice and guinea pigs determined by toxin neutralization test and enzyme-linked immunosorbent assay. Biologicals 22:215-219.

10. Kaulmann A, André CM, Schneider YJ, Hoffmann L, Bohn T (2016) Carotenoid and polyphenol bioaccessibility and cellular uptake from plum and cabbage varieties. Food Chem 197:325-332.

11. Maheshwari DT, Yogendra Kumar MS, Verma SK, Singh VK, Singh SN (2011) Antioxidant and hepatoprotective activities of phenolic rich fraction of Seabuckthorn (Hippophaerhamnoides L.) leaves. Food ChemToxicol 49:2422-2428. 
12. Manach C, Scalbert A, Morand C, Rémésy C, Jimenez L (2004) Polyphenols: food sources and bioavailability. Am J ClinNutr 79:727-747.

13. Michielan A, D'Incà R (2015) Intestinal permeability in inflammatory bowel disease: pathogenesis, clinical evaluation, and therapy of leaky gut. Mediators inflamm. https://doi.org/10.1155/2015/628157

14. Mohammad Azmin SN, Abdul Manan Z, Wan Alwi SR, Chua LS, Mustaffa AA, Yunus NA (2016) Herbal processing and extraction technologies. Sep Purif Rev 45:305-320.

15. Olas B, Skalski B, Ulanowska K (2018) The Anticancer Activity of Sea Buckthorn [Elaeagnusrhamnoides (L.) A. Nelson]. Front Pharmacol. https://doi.org/ 10.3389/fphar.2018.00232.

16. Patil VP, Kurhade SD, Devdhe SJ, Kale SH, Wakte PS (2012) Determination of Gallic Acid by HPTLC as Quality Control Parameter in Herbal Formulation: Triphalachurna. Int J ChemAnalSci 3: 1546-1549.

17. Rahman SU, Li Y, Huang Y, Zhu L, Feng S, Wu J, Wang X (2018) Treatment of inflammatory bowel disease via green tea polyphenols: possible application and protective approaches. Inflammopharmacology 26:319-30.

18. Rakesh SU, Salunkhe VR, Dhabale PN, Zburade KB (2009) HPTLC method for quantitative determination of gallic acid in hydroalcoholic extract of dried flowers of Nymphaea stellata Willd. Asian J Res Chem 2:131-134.

19. Ramachandran U, Divekar HM, Grover SK, Srivastava KK (1990) New experimental model for the evaluation of adaptogenic products. J Ethnopharmacol. 29:275-281.

20. Roy M, Datta A (2019) Fundamentals of Phytochemicals. In: Cancer Genetics and Therapeutics. Springer, Singapore. https://doi.org/10.1007/978-98113-9471-3_3.

21. Roy P, Mandal P, Panda S, Roy SM, Subba A (2018) Pharmacognosy and phytochemical screening of some plant derived medicine to treat dysmenorrheal pain by the Rajbanshi Community. Pharmacogn J. 10 :738-746.

22. Saggu S, Gupta V, Sawhney RC, Banerjee PK, Kumar $\mathbf{R}$ (2006) Analysis of heavy metal in herbal extracts of high-altitude growing plants Hippophaerhamnoides and Rhodiola imbricata. Toxicol Int13: 111-117.

23. Sarian MN, Ahmed QU, Mat So'ad SZ, Alhassan AM, Murugesu S, Perumal V, Syed Mohamad SN, Khatib A, Latip J (2017) Antioxidant and antidiabetic effects of flavonoids: A structure-activity relationship-based study. Bio Med Res Int. https://doi.org/ 10.1155/2017/8386065.

24. Scalbert A, Williamson G. (2000) Dietary intake and bioavailability of polyphenols. J Nutr130:2073S2085 S.
25. Sharma P, Kirar V, Meena DK, Suryakumar G, Misra K (2012)Adaptogenic activity of Valerianawallichii using cold, hypoxia and restraint multiple stress animal model. Biomed Aging Pathol2:198-205.

26. Sharma P, Kumar R, Prasad R, Suryakumar G (2014) Anti-stress and Adaptogenic Potentials of Seabuckthorn (Hippophaerhamnoides L.). In: Seabuckthorn (Hippophae L.): A multipurpose wonder plant (Ed.:Virendra Singh). New Delhi, India, pp 418-426.

27. Sharma P, Suryakumar G, Singh V, Misra K, Singh SB (2015) In vitro antioxidant profiling of seabuckthorn varieties and their adaptogenic response to high altitudeinduced stress. Int j Biometeorol. 59:1115-1126.

28. Sharma P, Misra K (2018) Rhodiola sp.: The Herbal Remedy for High-Altitude Problems. In: Misra K, Sharma P, Bhardwaj A (eds) Management of High Altitude Pathophysiology, $1^{\text {st }}$ edn. Elsevier, London, pp81-90.

29. Singh AK, Paul AD, Tanveer N (2013) Bioactivity guided extraction of S eabuckthorn (Hippophaerhamnoides L ssp. Turkestanica) leaves. J Sci Indus Res 72:307-311.

30. Singh D, Tanwar H, Jayashankar B, Sharma J, Murthy S, Chanda S, Singh SB, Ganju L (2017) Quercetinexhibits adjuvant activity by enhancing Th2 immune response in ovalbuminimmunizedmice. BiomPharmaco 90:354-360.

31. Sun HX (2006) Adjuvant effect of Achyranthes bidentata saponins on specific antibody and cellular response to ovalbumin in mice. Vaccine 24:3432-3439.

32. Tanwar H, Singh D, Singh SB, Ganju L (2018) Antiinflammatory activity of the functional groups present in Hippophaerhamnoides (Seabuckthorn) leaf extract. Inflammopharmacology 26:291-301.

33. Tanwar H, Chanda S, Agrawal MJ (2019) Immunopotentiating activity of an herbal adjuvant: its benefits thereof. Int J Complement Alt Med 12:122-124.

34. Wisnuwardani RW, De Henauw S, Androustsos $\mathbf{O}$ et al (2019) Estimated dietary intake of polyphenols in European adolescents: the HELENA study. Eur J Nutr 58:2345-2363.

35. Yogendra KMS, Tirpude RJ, Maheshwari DT, Bansal A, Misra K (2013) Antioxidant and antimicrobial properties of phenolic rich fraction of Seabuckthorn (Hippophaerhamnoides L.) leaves in vitro. Food Chem 141:3443-3450. 